\title{
Bulimia nervosa symptomatology and body image disturbance associated with distance running and weight loss
}

\author{
David H. Gleaves MA, Donald A. Williamson PhD* and Richard D. Fuller MA* \\ Research Department, The Renfrew Center, Philadelphia, Philadelphia, USA; ${ }^{*}$ Department of Psychology, \\ Louisiana State University, Baton Rouge, Louisiana, USA
}

\begin{abstract}
To investigate the hypothesis that problems characteristic of eating disorders may often be associated with distance running, 20 women who had lost weight through distance running were compared with a control group who did not exercise and had not lost weight and a comparison group of bulimia nervosa patients. Dependent variables were measures of depression, bulimia nervosa symptomatology, and body image disturbance. No differences were found between the runner group and the normal controls. Bulimics differed from runners and controls on most measures. Thus, the results did not support the proposition that weight loss through running leads to problems related to eating and body image. The failure to find disturbances in body image in runners suggests that body image disturbances are not a direct result of weight loss, as suggested by some theorists.
\end{abstract}

Keywords: Bulimia nervosa, weight loss, body image, running, exercise, eating disorders

Exercise and, in particular, long-distance running has been hypothesized to be associated with psychopathology characteristic of anorexia and bulimia ${ }^{1-3}$. Psychopathology discussed has included depression and body image disturbance, in addition to aberrant eating behaviour. It has also been suggested that running can actually cause an eating disorder to develop.

In the past 10 years, several investigations have examined these hypotheses ${ }^{5-11}$. Most of these studies concluded that runners, as a whole, do not exhibit the psychopathology of eating disordered subjects ${ }^{12}$, although the hypothesis has found some support ${ }^{13-16}$.

Body image disturbance is a central psychopathological feature of anorexia ${ }^{17}$ and bulimia nervosa ${ }^{18}$. Although the existence of the phenomenon is well established, its aetiology is not as clear. There has been research which suggests that weight loss may

Excerpts from this paper were presented at the annual convention of the Southeastern Psychological Association, March 1991

Address for correspondence: David H. Gleaves, Research

Department, The Renfrew Center, 475 Spring Lane, Philadelphia, PA 19128, USA

(C) 1992 Butterworth-Heinemann Ltd

0306-3674/92/030157-04 play an important role in the development of body image distortion. The 'failure to adapt' hypothesis ${ }^{19}$ suggests that body image distortion occurs when individuals lose an amount of weight and 'fail to adapt' their perceptions to their new body size. That is, they may see their premorbid body size instead of their actual current body size.

In support of the failure to adapt hypothesis, body image distortion has been found in previously obese patients $\mathrm{s}^{20}$, and anorectics who have recently lost weight have been found to display greater body image distortion ${ }^{19}$. Later studies of the effects of weight loss on body image distortion have yielded inconclusive results ${ }^{21,22}$. These earlier tests of the 'failure to adapt' hypothesis of body image distortion studied persons who had lost weight primarily through dieting. Examination of body size perception of persons who had lost weight through exercise has not been conducted in a controlled investigation. Such an investigation provides an interesting test of the 'failure to adapt' hypothesis.

This study examined distance runners who had lost weight as a result of their exercising to determine if symptomatology associated with eating disorders, including depression and body image disturbance, were present. Runners who had lost weight were examined in attempt to study the 'failure to adapt' hypothesis, and because this particular subsample would seem to be particularly at risk for the development of the symptomatology in question. This supposition is based on several lines of research, including studies of the effects of weight loss on eating habits and mood in humans ${ }^{23,24}$ and research on body weight regulation and set point theory ${ }^{25}$.

A variety of eating disorder symptoms was measured in the study so that runners could be directly contrasted to bulimia nervosa patients and normal controls who had not lost a significant amount of weight. The bulimia nervosa group was included in order to contrast the weight loss group with a group with known levels of severe eating disorder pathology. Normal controls were included to determine whether the eating habits/attitudes and body image disturbances of runners were significantly different from a group of persons who had never lost weight and expressed no problems related to weight or body size. 


\section{Methods}

\section{Subjects}

A total of 60 subjects were studied with 20 subjects in each of the three groups. Bulimia nervosa subjects were female patients who presented for treatment at a psychiatric hospital or university psychology clinic specializing in the treatment of eating disorders. All of these subjects met the current DSM-III-R ${ }^{26}$ criteria for bulimia nervosa. The subjects were assessed by a doctoral-level graduate student in clinical psychology using a structured interview similar to that described by Williamson ${ }^{27}$, and all cases were reviewed by the supervising psychologist before a final diagnosis was determined.

Female runners were recruited from a running club and a $10-\mathrm{km}$ road race. Only those who had lost $4.5 \mathrm{~kg}$ or more were included, and only those who reported (on diet and weight loss questionnaire; see below) using exercise exclusively or predominantly as a weight loss method were included. The runners reported running a mean of $48 \mathrm{~km}^{\text {week }}{ }^{-1}$ and having lost a mean of $12.25 \mathrm{~kg}$ since beginning running a mean of 7.9 years previously. The subjects were asked to participate in a study of the psychological aspects of distance running, diet, and weight loss and were offered feedback as to the results of the study.

Female non-dieter/non-exerciser controls were recruited from a sample of undergraduate females. They were screened using the diet and weight loss questionnaire. To be included in the study normals were required to report never having weighed more than $4.5 \mathrm{~kg}$ over their present weight and not to report frequent dieting or exercising to control their weight. They received extra credit in psychology classes for their participation.

In the selection of subjects, efforts were made to achieve homogeneity in terms of age, weight, and socioeconomic status. This was done by choosing control subjects to match with the other groups, who already showed similarity for these variables.

\section{Materials}

Three categories of dependent variables were used in this study - measures of depression, bulimic symptomatology, and body image disturbance. All dependent variables had been found to be reliable and valid in previous research. The depression measures included the Beck Depression Inventory $(B D I)^{28}$, the Automatic Thoughts Questionnaire (ATQ) ${ }^{29}$, and the Ineffectiveness scale of the Eating Disorder Inventory $(E D I)^{30}$. The BDI is well-validated as a measure of depression severity ${ }^{28}$. The ATQ assesses the frequency of occurrence of automatic thoughts associated with depression. The ATQ possesses strong correlations with depression severity and has been found to discriminate significantly between subclinically depressed and non-depressed criterion groups ${ }^{29}$. The ineffectiveness scale of the EDI was designed to assess feelings of general inadequacy, insecurity, and worthlessness and has been found to correlate with other measures of depressive symptomatology ${ }^{30}$.
Measures of bulimic symptomatology included the Bulimia Test ${ }^{31}$ and the first three scales of the EDI (Drive for Thinness, Bulimia, and Body dissatisfaction). Research has shown the BULIT to have good test-retest reliability and validity ${ }^{31,32}$. The reliability and validity of the EDI has also been demonstrated adequately ${ }^{30}$.

Measures of body image disturbance were from the Body Image Assessment Procedure (BIA) ${ }^{33}$. The procedure involves selection of a silhouette of a female body frame which most closely resembles the subject's perception of her current (CBS) and ideal (IBS) body sizes. The procedure is simple to use and economical in time of administration. Previous research has demonstrated its reliability and validity $^{33}$.

A dieting and weight loss questionnaire, developed by the first author, was also used to help classify subjects in terms of weight loss methods and to screen controls. Some items on the questionnaire were derived from the Eating QuestionnaireRevised $^{34}$, which is a well-validated measure for assessing bulimia. The questionnaire asked subjects to rate the extent to which they were currently trying to lose or control their weight, amounts of weight they had lost, and the extent to which they used dieting versus exercise to achieve their weight loss.

\section{Design and procedures}

The battery of self-report tests and the body image assessment were administered at a university psychological services centre. The three groups (runners, bulimics, and controls) were then compared across the following dependent variables:

1. age, race, and body mass index (BMI; weight/ height ${ }^{2}$ ) to assess homogeneity of samples on these variables;

2. level of depressive symptomatology, operationally defined as scores on the BDI, ATQ and ineffectiveness scale of the EDI (EDII);

3. level of bulimia nervosa symptomatology, operationally defined as scores on the BULIT and the first three scales of the EDI - Drive for Thinness (EDIDT), Bulimia (EDIB), and Body Dissatisfaction (EDIBD);

4. perception of current body image, operationally defined as CBS from the Body Image Assessment, choice of ideal body size, operationally defined as IBS from the Body Image Assessment, and body dissatisfaction, operationally defined as the discrepancy score (Discrepancy; CBS minus IBS).

\section{Results}

The three groups were compared initially in terms of demographic and descriptive information. One-way analysis of variance was used to determine if differences existed among the groups on the variables age and BMI. Post hoc comparisons were made with Tukey's statistic. No significant differences were found for age or body mass among the three groups. All subjects were the same race (Caucasian). 
To examine group differences on the measures of depression, a multivariate analysis of variance (MANOVA) was computed using scores on the BDI, ATQ and EDII as dependent variables. Wilk's criterion was used for determining statistical significance. The overall MANOVA was significant, $F$ $(6110.25)=14.76, P<0.0001$. Univariate analyses were interpreted using the Bonferroni correction procedure to control the type 1 error rate. As three univariate analyses were computed, an $\alpha$-level of 0.017 was used. Group means and $F$ values for each variable are presented in Table 1 . The univariate analysis for the BDI found significant group differences. Post hoc comparisons of group means were made using Tukey's statistic. Bulimics differed from the two other groups which did not differ from each other. The same pattern of results was found for the ATQ and the EDII with bulimics differing from the two other groups and no significant difference between runners and controls.

As BMI was found to be significantly correlated with the bulimia and body image measures, analysis of covariance was used with BMI as the covariate to control for influences due to body size for these variables. The homogeneity of regression assumption was tested and met for both sets of variables. For the bulimia measures, a multivariate analysis of covariance (MANCOVA) with BMI as the covariate was found to be statistically significant, $F(8106)=27.36$,
$P<0.0001$. The Bonferroni correction procedure was again used to guard against type 1 error inflation. Four univariate analyses were computed and thus an $\alpha$-level of 0.0125 was used. Post hoc comparisons were made with the Bryant-Paulson procedure, a generalization of Tukey's statistic for analysis of covariance. The results of the univariate analyses and post hoc comparisons are presented in Table 2. There were significant group effects on all four dependent variables. The same pattern of post hoc results was found. Bulimics scored higher on all dependent variables (i.e. BULIT, EDIDT, EDIB, EDIBD) in comparison with the other groups who did not differ among themselves.

To examine the data from the Body Image Assessment, analysis of covariance (ANCOVA) was used with BMI as the covariate. Multivariate analyses were not used because the variables are linearly dependent. The Bonferroni correction procedure was again used and an $\alpha$-level of 0.017 was set. Post hoc comparisons of group means were made with the Bryant-Paulson procedure. These analyses are presented in Table 3 . There were significant group effects for all three variables. The same general pattern as above was found for post hoc procedures. Bulimics differed from runners and controls but no other comparisons were significant for CBS and discrepancy scores. For IBS, the difference between bulimics and controls was not statistically significant.

Table 1. ANOVA results and mean values for the depression measures

\begin{tabular}{|c|c|c|c|c|c|}
\hline Depression measure & Runners & Controls & Bulimics & $F$ & $P$ \\
\hline $\begin{array}{l}\text { BDI } \\
\text { ATQ } \\
\text { EDII }\end{array}$ & $\begin{array}{c}3.30_{\mathrm{a}}(3.61) \\
41.10_{\mathrm{a}}(13.82) \\
0.80_{\mathrm{a}}(2.46)\end{array}$ & $\begin{array}{c}4.80_{\mathrm{a}}(4.10) \\
41.50_{\mathrm{a}}(12.99) \\
1.60_{\mathrm{a}}(2.09)\end{array}$ & $\begin{array}{l}20.65_{b}(8.22) \\
85.40_{b}(22.10) \\
12.80_{b}(8.21)\end{array}$ & $\begin{array}{l}56.95 \\
45.87 \\
34.95\end{array}$ & $\begin{array}{l}<0.0001 \\
<0.0001 \\
<0.0001\end{array}$ \\
\hline
\end{tabular}

Values are mean(s.d.)

Means having the same subscript are not significantly different at $P<0.05$

Table 2. ANCOVA results and adjusted mean values for the bulimia measures

\begin{tabular}{|c|c|c|c|c|c|}
\hline Bulimia measure & Runners & Controls & Bulimics & $F$ & $P$ \\
\hline $\begin{array}{l}\text { BULIT } \\
\text { EDIB } \\
\text { EDIDT } \\
\text { EDIBD }\end{array}$ & $\begin{array}{r}51.25_{\mathrm{a}}(2.88) \\
0.60_{\mathrm{a}}(0.74) \\
4.49_{\mathrm{a}}(0.96) \\
11.51_{\mathrm{a}}(1.53)\end{array}$ & $\begin{array}{r}46.20_{a}(2.89) \\
0.78_{a}(0.74) \\
1.84_{a}(0.96) \\
8.84_{a}(1.53)\end{array}$ & $\begin{array}{r}120.80_{b}(2.88) \\
9.12_{b}(0.74) \\
13.07_{b}(0.96) \\
17.59_{b}(1.53)\end{array}$ & $\begin{array}{r}208.67 \\
42.97 \\
37.55 \\
8.56\end{array}$ & $\begin{array}{l}<0.0001 \\
<0.0001 \\
<0.0001 \\
<0.001\end{array}$ \\
\hline
\end{tabular}

Values are adjusted mean(s.d.)

Means having the same subscript are not significantly different at $P<0.05$

Table 3. ANCOVA results and adjusted mean values for the body image measures

\begin{tabular}{|c|c|c|c|c|c|}
\hline Body image measure & Runners & Controls & Bulimics & $F$ & $P$ \\
\hline $\begin{array}{l}\text { CBS } \\
\text { IBS } \\
\text { Discrepancy }\end{array}$ & $\begin{array}{l}4.15_{\mathrm{a}}(0.31) \\
3.44_{\mathrm{a}}(0.21) \\
0.71_{\mathrm{a}}(0.37)\end{array}$ & $\begin{array}{c}4.08_{\mathrm{a}}(0.31) \\
3.24_{\mathrm{ab}}(0.21) \\
0.83_{\mathrm{a}}(0.37)\end{array}$ & $\begin{array}{l}5.57_{b}(0.31) \\
2.52_{b}(0.21) \\
3.05_{b}(0.37)\end{array}$ & $\begin{array}{r}7.31 \\
5.40 \\
12.49\end{array}$ & $\begin{array}{l}<0.002 \\
<0.01 \\
<0.0001\end{array}$ \\
\hline
\end{tabular}

Values are adjusted mean(s.d.)

Means having the same subscript are not significantly different at $P<0.05$ 


\section{Discussion}

Comparisons of runners, normal controls, and bulimics on a variety of measures of eating disorder symptoms yielded consistent results - runners and controls did not differ, and bulimics were significantly more disturbed that runners or controls. Based on these data, the hypothesis that weight loss via running results in problems related to eating disorders was not supported. These results call into question the conclusions of others that runners resemble persons with an eating disorder ${ }^{2,3}$ or that running commonly leads to the development of an eating disorder". The results are consistent with earlier findings that runners are generally indistinguishable from normals without excessive concern over eating or weight $t^{5-11}$.

These data also question the theory that body image disturbance develops solely as a result of losing weight. Runners in this study had lost a mean of $12.25 \mathrm{~kg}$ and yet no differences were found in CBS between the runners and the control group who had never weighed more than $4.5 \mathrm{~kg}$ above their current weight.

The results of this study add to the current body of research in two distinct ways. First, instead of examining runners in general, a specific subsample which one would predict to be especially at risk for the development of eating disorder symptomatology was studied. No signs of such symptomatology were detected. Second, the study examined greater amounts of weight loss than the previous investigations of the failure to adapt theory of body image disturbance, and the theory was still not supported.

In summary, the results of this study do not suggest that bulimia nervosa psychopathology is frequently associated with distance running, or weight loss through distance running. As there are definite health benefits to regular exercise, our society's preoccupation with thinness and weight loss need not necessarily be regarded as pathological. Quite the opposite, it may be healthy, both physically and psychologically.

\section{References}

1 Smith NJ. Excessive weight loss and food aversion in athletes simulating anorexia nervosa. Pedia 1980; 66: 139-42.

2 Sours JA. Starving to Death in a Sea of Objects: The Anorexic Syndrome. London: Jason Aronson, 1980: 259-60.

3 Yates A, Leehey K, Shisslak CM. Running - an analogue of anorexia? N Engl J Med 1983; 308: 251-5.

4 Katz JL. Long distance running, anorexia nervosa, and bulimia: a report of two cases. Compr Psychiatry 1986; 27: 74-8.

5 Blumenthal JA, O'Toole LC, Chang JL. Is running an analogue of anorexia nervosa? JAMA 1984; 252: 520-3.

6 Goldfarb LA, Plante TG. Fear of fat in runners: an examination of the connection between anorexia nervosa and distance running. Psychol Rep 1984; 55: 296.

7 Knight PO, Schocken DD, Powers PS, Feld J, Smith JT. Gender comparison in anorexia nervosa and obligate running. Med Sci Sports Exerc 1987; 19 (April Suppl): S66.
8 McCrutcheon L, Ayres A. Are runners really like anorexics? Runn Times 1983; June: 14-16.

9 Nudelman S, Rosen JC, Leitenberg H. Dissimilarities in eating attitudes, body image distortion, depression and self-esteem between high intensity male runners and women with bulimia nervosa. Int J Eat Dis 1988; 7: 625-34.

10 Warren BJ, Stanton AL, Blessing DL. Disordered eating patterns in competitive female athletes. Int J Eat Dis 1990; 9: 565-9.

11 Wheeler GD, Wall SR, Belcastro AN, Conger MA, Cumming DC. Are anorexic tendencies prevalent in the habitual runner? Br J Sports Med 1986; 20: 77-81.

12 Thompson JK. Body Image Disturbance: Assessment and Treatment. New York: Pergamon Press, 1990.

13 Borgen JS, Corbin CB. Eating disorders among female athletes. Phys Sportsmed 1987; 15: 89-95.

14 Brownell KD, Rodin J, Wiomore JH. Eat drink, and be worried?. Runners World 1988; August: 28-34.

15 Henry S. The price of perfection. The Runner 1982; March: 35-9.

16 Pasman L, Thompson JD. Body image and eating disturbance in obligatory runners, weight lifters, and sedentary individuals. Int J Eat Dis 1988; 7: 759-70.

17 Bruch H. Eating Disorders. London: Routledge, 1974.

18 Schlesier-Stroop B. Bulimia: a review of the literature. Psychol Bull 1984; 95: 247-57.

19 Crisp AH, Kalucy RS. Aspects of the perceptual disorder in anorexia nervosa. Br J Med Psychol 1974; 47: 349-61.

20 Glucksman $M$, Hirsh $L$. The response of obese patients to weight reduction: III. The perception of body size. Psychosom Med 1969; 31: 1-7.

21 Gorham SJ, Hundleby JD. Present body perception and prior weight reduction in young adult women. Int J Eat Dis 1988; 7: 407-11.

22 Slade PD. Awareness of body/image dimensions during pregnancy: an analogue study. Psychol Med 1977; 7: 245-52.

23 Keys A, Brozek J, Henschel A, Michelson O, Taylor HL. The Biology of Human Starvation. Minneapolis: University of Minnesota Press, 1950.

24 Bruch $\mathrm{H}$. Psychological aspects of reducing. Psychosom Med 1952; 14: 337-46.

25 Keesey RE, Powley TL. The regulation of body weight. Ann Rev Psychol 1986; 37: 109-33.

26 American Psychiatric Association. DSM-III-R. Diagnostic and Statistical Manual of Mental Disorders, 3rd ed. (revised). Washington DC: American Psychiatric Association, 1987.

27 Williamson DA. Assessment of Eating Disorders: Obesity, Anorexia, and Bulimia Neroosa. New York: Pergamon Press, 1990.

28 Beck AT, Steer RA, Garbin MG. Psychometric properties of the Beck Depression Inventory: twenty-five years of evaluation. Clin Psychol Rev 1988; 8: 77-100.

29 Hollon SD, Kendall PC. Cognitive self-statements in depression: development of the Automatic Thoughts Questionnaire. Cogn Ther Res 1980; 4: 383-95.

30 Garner DM, Olmsted MA, Polivy J. Development and validation of a multidimensional eating disorder inventory for anorexia nervosa and bulimia. Int J Eat Dis 1983; 2: 15-34.

31 Smith MC, Thelen MH. Development and validation of a test for bulimia. J Consult Clin Psychol 1984; 52: 863-72.

32 Williamson DA, Goreczny AJ, Duchmann EG. Behavioral and psychophysiological assessment of bulimia. Ann Behav Med 1987; 9: 8-11.

33 Williamson DA, Davis CJ, Bennett SM, Goreczny AJ, Gleaves DH. Development of a simple procedure for assessing body image disturbance. Behavioral Assessment 1989; 11: 433-46.

34 Williamson DA, Davis CJ, Goreczny AJ, Bennett SM, Watkins PC. The eating questionnaire - revised: a new symptom checklist for bulimia. In: Keller PA, Ritt LG, eds. Innovations in Clinical Practice: A Source Book. Sarasota, Florida: Professional Resources Exchange, 1989. 